University of Nebraska - Lincoln

DigitalCommons@University of Nebraska - Lincoln

June 1993

\title{
Ecosystem Valuation: Combining Economics, Philosophy, and Ecology
}

F. Gregory Hayden

University of Nebraska-Lincoln, ghayden1@unl.edu

Follow this and additional works at: https://digitalcommons.unl.edu/econfacpub

Part of the Economics Commons

Hayden, F. Gregory, "Ecosystem Valuation: Combining Economics, Philosophy, and Ecology" (1993). Economics Department Faculty Publications. 15.

https://digitalcommons.unl.edu/econfacpub/15

This Article is brought to you for free and open access by the Economics Department at DigitalCommons@University of Nebraska - Lincoln. It has been accepted for inclusion in Economics Department Faculty Publications by an authorized administrator of DigitalCommons@University of Nebraska - Lincoln. 


\title{
Ecosystem Valuation: Combining Economics, Philosophy, and Ecology
}

\author{
F. Gregory Hayden
}

Discussions regarding ecological srises often begin by casually identifying anthropocentric traits as responsible for the crises and by briefly explaining the need for holistic or macroscopic modeling. Yet, when modeling begins, policy scientists, philosophers, and social scientists usually are not included, and the models often are not ecological, but are rather narrowly biological or physical. The main purpose of this paper is to emphasize the need for broader and richer modeling and the need to recognize that environmental protection and enhancement is anthropocentric policymaking. The question is not whether it will be anthropocentric, but which anthropocentric values, beliefs, and philosophies will guide the policymaking paradigms and analytical techniques.

\section{The Need for Context and Criteria}

Deliveries and consequences between what we call a natural organism and a social organism are the means for each other so that neither can be understood nor valued separately from the other. To think about the qualities of a thing "is to look at a thing in its relations with other things, and such judgment often

The author is Professor of Economics at the University of Nebraska-Lincoln. This paper was presented at the annual meeting of the Association for Evolutionary Economics, Anaheim, California, January 5.7, 1993. 
modifies radically the original attitude of esteem and liking" [Dewey 1958, 123]. An entity that is valued highly is one "which serves certain ends, that which stands in certain connections with consequences. Judgment of value is the name of the act which searches for and takes into consideration these connections" [Dewey 1958, 123]. Both economic and ecological professionals have ignored Dewey's advice regarding deliveries, connections, and consequences among related entities, so that most standards and principles of ecological valuation are based on what Alfred Whitehead called the fallacy of misplaced concreteness.

Policy scientists must be context specific. A contextual approach means that an investigator does "not flatten out all decisions into interchangeable units of individual welfare, but instead retains a sensitivity toward different types and scales of impacts" [Norton 1991, 6]. The flattening-out approach to evaluation-the measuring of welfare according to a single scale of indicators such as dollars-ignores differences in the different kinds of consequences [Norton 1991, 6].

In addition to criteria and context being needed to model and analyze, Herman Daly and John Cobb suggest two rules of advice from Whitehead about how to avoid toxic levels of abstractness. One is, in Whitehead's words, "recurrence to the concrete in search of inspiration," and the second is to avoid excessive professional specialization [Daly and Cobb 1989, 41].

\section{Changing the Ideological Metaphor}

Concern for criteria, context, and concreteness becomes a call for a change from the neoclassical maximization metaphor. The concern for concrete criteria for a concrete context requires a different metaphor. It is a metaphor that includes limits, sufficiency, policy relevance, and multidimensionality. It is a metaphor that emphasizes improvement rather than growth.

Changing the ideological metaphor allows recognition that welfare is increased by decreasing options, by limiting production, and by guiding technology. It allows recognition that investment spending and increases in GDP can reduce welfare [see Leipert and Simonis 1990]. 


\section{Integration of Social and Ecological Paradigms}

In her book, Crafting Institutions [1992], Elinor Ostrom explains that many economic infrastructure projects around the world have failed because institutions were ignored-both the analysis of current institutions and the crafting of new institutions are necessary to make projects function. Project modeling has usually been the exclusive domain of engineers and costbenefit analysts, to the detriment of projects. Although Ostrom's main concern was with irrigation projects in Third World countries, the same kind of problem exists with regard to the modeling and analysis of the environment. Most analyses are completed by ecologists and neoclassical economists. The two usually ignore each other's analysis, and they both ignore institutions and the crafting of new institutions.

In the remainder of this paper, I attempt to define an approach for a relevant decision domain in which social institutions and environmental functions both operate. The context of environmental problems is broadly illustrated in Figure 1. The components in Figure 1 have been explained elsewhere [Swaney 1987; Hayden 1988]. The importance of the digraph for the purpose here is twofold. The first is to demonstrate that a purely environmental problem does not exist. Environmental components are embedded in larger systems. As indicated in Figure 1, real world systems include (1) cultural values, (2) societal beliefs, (3) social institutions, (4) personal attitudes, (5) technology, and (6) the natural environment, all of which should be included in serious modeling of an "environmental problem."

A second important point revealed in Figure 1 is that technology delivered and applied to the environment is delivered through institutions, and the substances and functions provided from the environment are delivered to institutions. In one sense, this simplifies modeling by clarifying that direct deliveries do not occur between the environment and components other than institutions. In another sense, it complicates analysis because searching out the relationships among other components that indirectly influence the institutional-environmental nexus is difficult.

Additional complexity obtrudes itself upon the analysis because of our knowledge about institutions and the environment. There is never a direct relationship between any one institution and an environment. No institution operates alone. Institutions 
Figure 1. Relationships among Values, Beliefs, Attitudes, Institutions, Technology, and the Environment

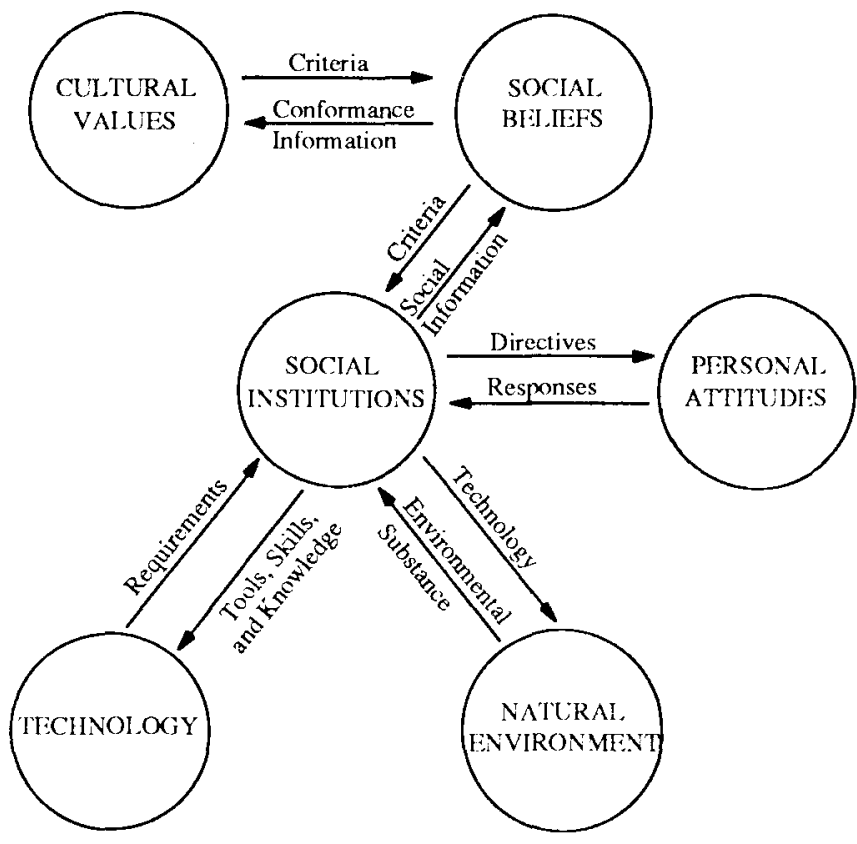

overlap with institutions in any social endeavor; thus, institutions work through institutions in transaction with the environment.

The wetland models articulated in Figure 2 (and they are the predominant kind in the literature) are incomplete. No one can find a wetland that is separate from human institutions (or articulated differently, and more correctly, real world wetland systems are not natural systems). It is not possible to isolate a wetland as a system and then take account of the impact of an "outside force" on it as a system. First, "the force" is really numerous and varied forces, or deliveries. Second, they are not outside because no institution ever operated apart from a natural environment. Just as no institution ever existed apart from an environment, deliveries from an environment, as outlined in Figure 1, should not be thought of as being exclusively delivered by environments. Most deliveries from environments are taken by institutions. Thus, one of the main tasks of environmental policy is crafting appropriate institutions. 
Figure 2. Wetland Ecosystem Model

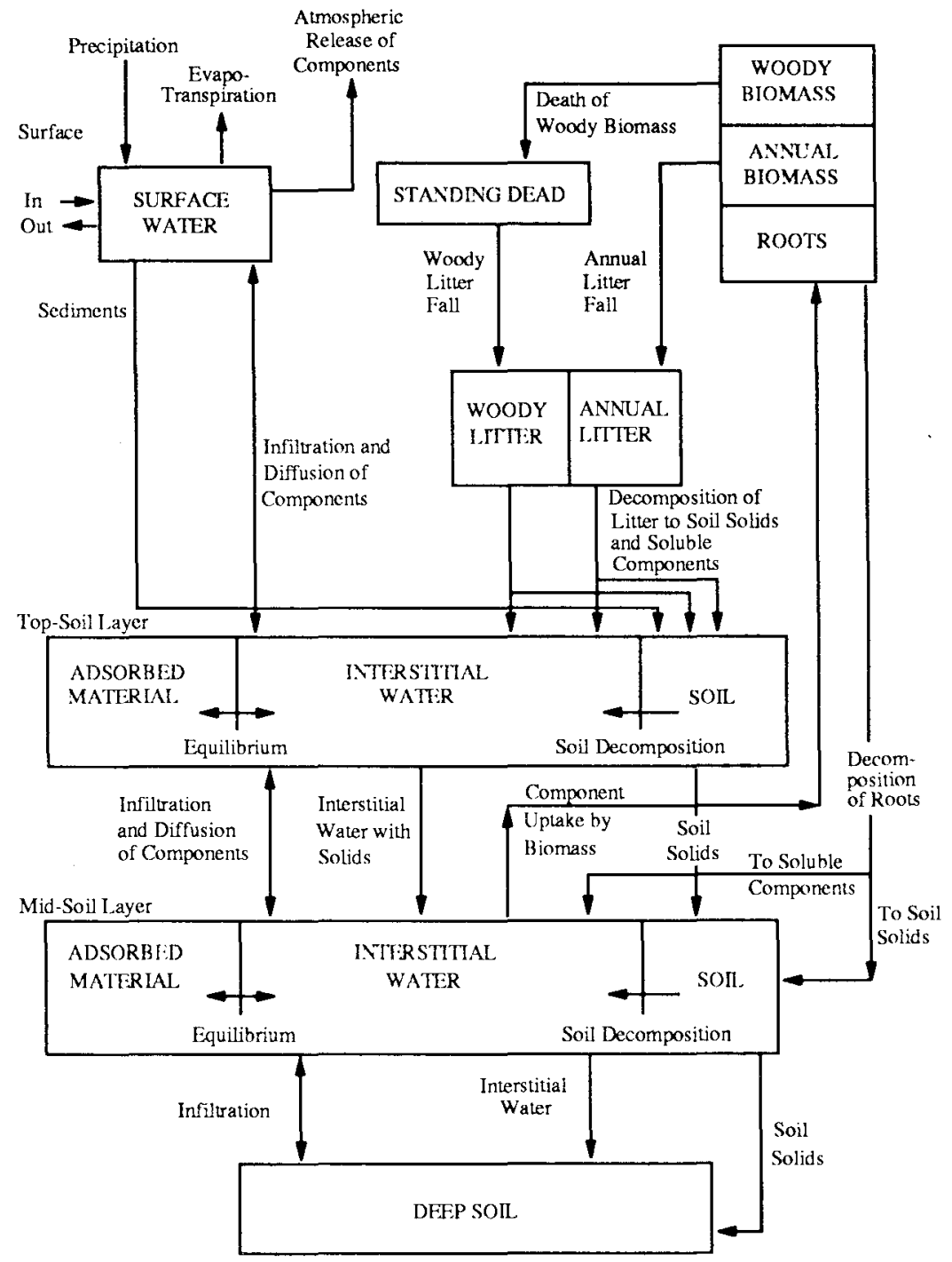

Source: Kadlec and Hammer [1988]. 
Third, each of numerous institutional entities is likely to be related, in terms of delivery, to a number of different kinds of environmental entities. An example is found in a U.S. Environmental Protection Agency report on a particular anthropogenic stress in the environment. The stress is a xenobiotic organic chemical delivery that is toxic to biota and is associated with 19 different problem areas. The association includes various institutions and their deliveries, such as mining wastes and agricultural pesticides; numerous mediums for delivery, such as sludge and ground water; and diverse receiving nodes, such as wildlife food sources and human water sources [EPA 1990, 10-11].

If we recognize the regular exchange between the environment and social institutions, then concepts such as ecological sustainability and biodiversity become much more difficult to define separate from a particular context and much more difficult to apply in a context. Ecological sustainability has a social meaning because ecologies have a social context, as is also the case for biodiversity. Alternative ecological sets need to be defined and considered for each alternative context. It is not sufficient to think that the same wetland will be treated differently depending on different technological and social habits. The wetland itself changes with a different technological and social regime. The kinds of ecological functions and species to be sustained vary as the socioecological process changes. God is not the only concept that is in the details-to paraphrase Einstein-so are wetlands. If gold mining tailings are dumped in a wetland, the details have changed. The kind of chemicals and their form change with each different transactional context. To answer questions about biodiversity and sustainability, human groups, their technologies, and their institutions are significant and need to be so recognized in modeling.

When modeling with a concern for sustainability, contextual specificity requires knowledge about which cycle is relevant. What point in the cycle is being modeled? Will an attempt be made to freeze the ecological component in its current cycle? In a six- to eight-year cycle of biotic vegetarian-muskrat alteration, muskrat sustainability efforts can only coincide at one cycle in the alternating succession. Under conditions of autogenic succession, wetlands in a natural setting are completely destroyed. Wetlands gradually fill because of erosion of mineral material and the accumulation of organic material. Eventually, the water becomes shallow enough to support marsh vegetation and build a peat mat [Mitsch and Gos- 
selick 1986, 151]. Thus, an attempt to sustain a wetland and all its immense array of life is "unnatural." (It may be that the only conditions under which constant sustainability can exist are those under anthropocentric control such as the U.S. corn belt, where, at considerable expense, a particular kind of ecosystem is sustained.)

Those edges (deliveries and connections) in the socioecological digraph, which are to be defined for policy purposes, should be defined in order that sufficiency flow decisions can be determined. Figure 3 can be used to visualize the meaning of a sufficiency delivery concept. Assume factory $\mathbf{J}$ in Figure 3 is delivering pollution to wetland $\mathrm{K}$. In a sufficiency model, the delivery carrying capacity would be limited by what is sufficient to meet the contextual criteria of the process. For simplicity, assume that the dimensions of concern are $m$ and $n$. If $m$ and $n$ are consequent indexes, they should be designed to indicate the results of the factory pollution on a species, ecosystem function, or ecosystem service. Although they are different dimensions of the flow from $\mathrm{J}$ to $\mathrm{K}, \mathrm{m}$ and $\mathrm{n}$ can be normalized around a common zero point at point $\mathrm{A}$. The common zero point is the flow level that has been normalized to make a particular system viable. Determining what level of chemical discharge into a wetland is tolerable depends on the system to be sustained. The zero point indicates zero deviation from the ecosystem normality that decision makers are attempting to achieve.

Let us assume the spectrum index across the top of Figure 4 represents $m$ (from Figure 3) and the similar index on the left side of Figure 4 represents dimension $n$. They have several relevant points. Points $A$ and $A^{\prime}$ represent the viable flow level of a species or ecosystem function or service; the flow level necessary for process sufficiency. Any point on the positive side of the index indicates positive flow levels that are greater than necessary, and to the right are negative flow levels that are less than necessary for the normalized sufficiency. As in any process, some deviation from the norm is allowed; deviation limits are established to indicate the deterioration of the socioecological system. Points B, B', C, and $\mathrm{C}^{\prime}$ represent system disruption without irreversibility or extinction being reached. Points $\mathrm{C}$ and $\mathrm{C}^{\prime}$ represent the point at which too much is being introduced in order to keep the process viable. Points $B$ and $B^{\prime}$ represent not enough. As an example, the water 


\section{Figure 3. Delivery Criteria Indicies ( $m$ and $n$ )}

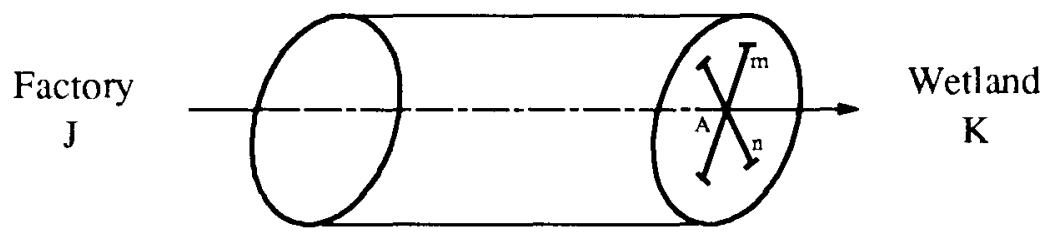

cleansing and aeration function of a tortuous turbulent river is depleted when the river is dredged and the channel straightened.

Points $D$ and $D^{\prime}$ represent the point of irreversibility of an ecosystem function or species. Points $E$ and $E^{\prime}$ represent extinction of an ecosystem species, function, or service. As an example, excessive numbers of bovine have been introduced in ecosystems around the world, causing the extinction of plant species. Points $F$ and $F^{\prime}$ indicate a situation in which the socioecological system is providing a flow delivery level that is too small to maintain the environmental function or species. For example, fecal matter flowing from a lake may be blocked by an economic project. As the flow level is decreased, a point is reached that creates severe disease problems for habitating species. Points $G$ and $G^{\prime}$ indicate a species or environmental service has reached the level of extinction.

As the criteria represented in each index are applied to the policy decision context QRTS, decisions outside of WXYZ are excluded from consideration in order to maintain system viability and integrity. For example, a decision for a technology that would place flows in the BYUS area would not be acceptable. A more complete explanation of Figure 4 is available in its original source [Hayden 1992]; however, the explanation here is adequate to give direction to instrumental analysis. The task of instrumental policy analysis is to resolve dichotomies into sufficiency norms and design relevant indicators to represent those norms as well as to measure deviations from the norms. 


\section{Figure 4. Decision Context with Two Indices}

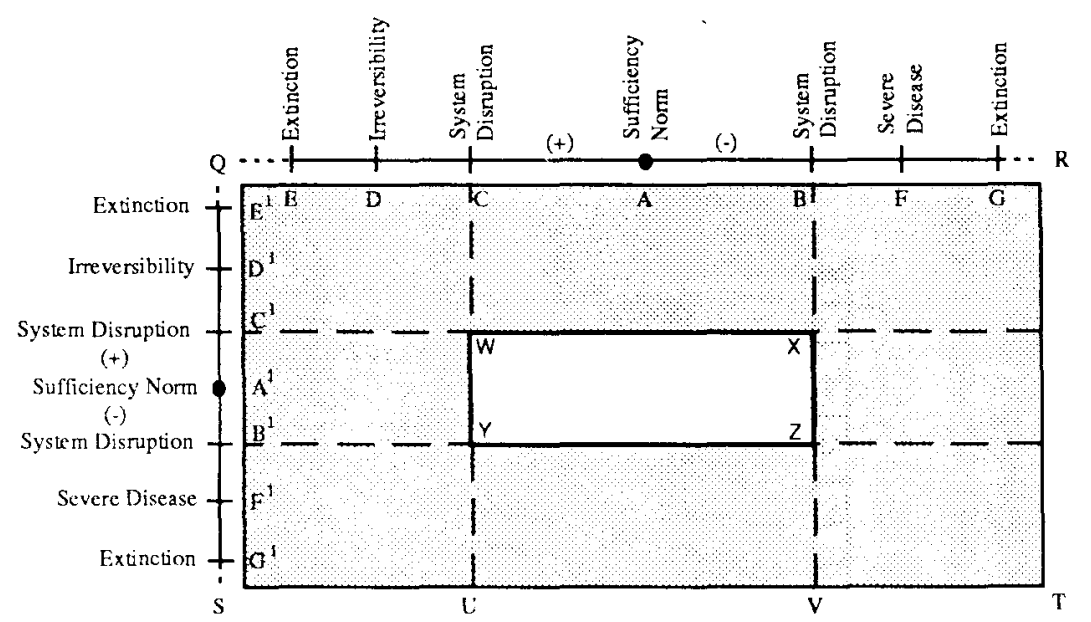

Source: Hayden [1992].

\section{Ideological Impediments}

Clarence Ayres taught us that it is important to explain the ideological impediments that prevent appropriate analysis. Our progress in designing transactional ecosystem models has been so meager because paradigms in both economics and ecology have been guided by the belief that some universal presence leads to sustainable equilibrium through maximization. In an article about ecological communities, Richard Levins wrote that "despite assertions that communities evolve to maximize stability or efficiency or information or complexity or anything else, there is no necessary relation between evolution within the component species and evolution of macroscopic community properties" [1975, 48-49]. Yet these claims continue to be made and are attractive to economists and biologists. "Perhaps the reason for this is a frequent reference by biologists to a philosophical framework that seeks harmony in nature. Or it may be the transfer to ecology of the equally invalid Adam-Smithian assertation in the economics of capitalism, that some hidden hand converts the profit-maximizing activities of individual companies into some social good" [Levins 1975, 49]. 
Adam Smith was expressing a more general Western myth. The Western mind holds a whole set of noninterference beliefs, examples of which include: "Pray to God and everything will take care of itself "; "Natural species provide for a sustainable environment"; "Do not interfere with the market lest chaos be created through disequilibrium"; and "Mutation will provide the variation for natural selection to favor." The noninterference equilibrium model of the invisible hand is so pervasive that it is sometimes used to create a common denominator between animal behavior and economic institutions. This was demonstrated in a federal research grant application. The university professors who wrote the application asserted that, "work on foraging behavior in animals in the laboratory has provided good test models for complex theories of economic decision making."

With the ideology of sustainable equilibrium, systems are metaphysical enigmas that are guided by invisible supernatural forces. The mystery of life is solved. The complexity and dynamics of open living systems are replaced by elegant simplicity. Efficiency in an environmental system, as in the market system, is achieved by the same policies. In ecology, as with Adam Smith, the more competition, and the more diverse the competition, the better for the system. More species and more diverse kinds of species; more firms and more diverse kinds of production-both configurations provide for efficiency. Institutional economists have taken issue with the assumption of the invisible hand and sustainability theories in economics; they need to be equally suspicious of the same kinds of theories in the biological sciences.

Levins reports on studies in dynamic biogeography that have not found sustainable equilibrium in natural settings. Biologists have found surprisingly high turnover rates of species on islands and other isolated patches [for references, see Levins 1975, 47]. They also have determined that "the turnover rates of species depend on their whole environment, including the structures of the communities in which they live and on the genetic make-up of the local populations" [Levins 1975, 47].

\section{Conclusion}

Many researchers in biology and ecology are arriving at the same methodological position as those in institutional economics: the study of individual parts will not allow us to understand the 
parts or the whole. Neither the parts nor the whole are given by any iron law of nature in either ecology or economics. They are more and more given by technology and institutions. Humans must decide upon the kind of technology, institutions, and environment. Therefore, we are led back to instrumental philosophy to decide what to study and how to study it. For instrumental valuing, concerns about criteria, concreteness, and context come to the fore. Dichotomies need to be resolved into system sufficiency norms, and sustainability and biodiversity need to be instrumentally judged in the context of the whole socioecological process.

\section{References}

Daly, Herman E., and John B. Cobb, Jr. For the Common Good: Redirecting the Economy toward Community, the Environment, and a Sustainable Future. Boston: Beacon Press, 1989.

Dewey, John. Experience and Nature. New York: Dover Publications, Inc., 1958.

F. Gregory Hayden. "An Alternative to the Safe Minimum Standard for Environmental Planning." Paper presented at the annual conference of the European Association for Evolutionary Economy. Ministere de la Recherche et la Technologie, Rue Decartes. Paris, France. November 4-6, 1992.

"Values, Beliefs, and Attitudes in a Sociotechnical Setting." Journal of Economics Issues 22 (June 1988): 415-26.

Kadlec, Robert H., and David E. Hammer. "Modeling Nutrient Behavior in Wetlands." Ecological Modeling 40 (March 1988): 37 66.

Kenney, Anthony. "Criterion." In Encyclopedia of Philosophy, edited by Paul Edwards, 258-261. New York: Macmillan Company, 1967.

Leipert, Christian, and Uno Simonis. "Environmental DamageEnvironmental Expenditure 1: Statistical Evidence on the Federal Republic of Germany." The Environmentalist 10 (December 1990): 301-309.

Levins, Richard. "Evolution in Communities Near Equilibrium." In Ecology and Evolution of Communities. Cambridge, Mass: Harvard University Press, 1975. 
Liebhafsky, H. H. "Peirce on the Summum Bonum and the Unlimited Community; Ayres on 'The Criterion of Value'." Journal of Economic Issues 20 (March 1986): 5-20.

Mitsch, William J., and James G. Gosselink. Wetlands. New York: Van Nostrand Reinhold Company, Inc., 1986.

Norton, Bryan. Toward Unity Among Environmentalists. New York: Oxford University Press, 1991.

Ostrom, Elinor. Crafting Institutions for Self-Governing Irrigation Systems. San Francisco: C.S. Press, 1992.

Soderbaum, Peter. "Environmental Management: A Non-Traditional Approach." Journal of Economic Issues 21 (March 1989): 139-165.

Swaney, James. "Elements of a Neoinstitutionalist Environmental Approach." Journal of Economics Issues 21 (December 1987): 1739-1780.

U.S. Environmental Protection Agency. Relative Risk Reduction Program: The Report of the Ecology and Welfare Subcommittee. Washington, D.C.: EPA SAB-90-021A, 1990. 